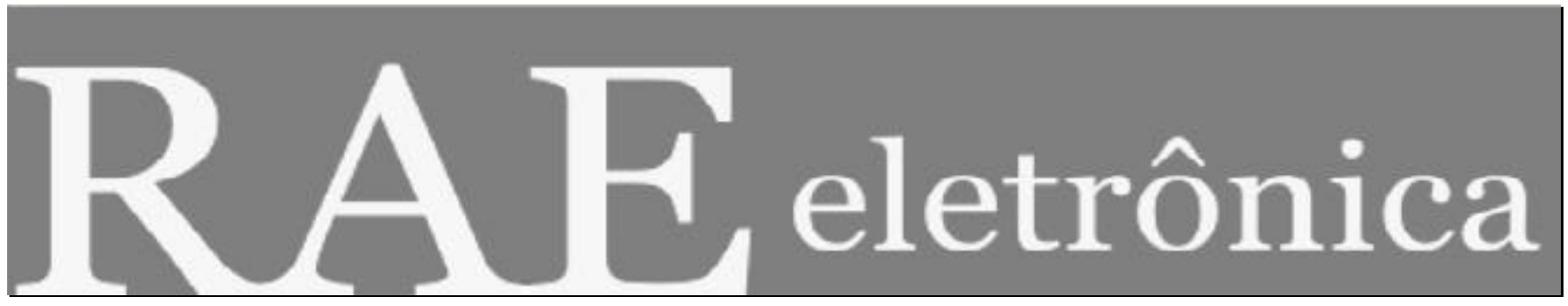

\title{
SELEÇÃO DE CURSOS DE EDUCAÇÃO CONTINUADA POR EXECUTIVOS DE EMPRESAS
}

Por:

Edmilson Alves de Moraes, FGV-EAESP

Alexandre Reis Graeml, UNICENP e UFPR

Otávio Próspero Sanchez, FGV-EAESP

Frederico Scott Brusa Mesquita, FGV-EAESP

RAE-eletrônica, v. 5, n. 2, Art. 13, jul./dez. 2006

http://www.rae.com.br/eletronica/index.cfm?FuseAction=Artigo $\& I D=2058 \&$ Secao=ARTIGOS $\&$ Volume $=5$ $\&$ Numero $=2 \& A n o=2006$

CCopyright, 2006, RAE-eletrônica. Todos os direitos, inclusive de tradução, são reservados. É permitido citar parte de artigos sem autorização prévia desde que seja identificada a fonte. A reprodução total de artigos é proibida. Os artigos só devem ser usados para uso pessoal e não-comercial. Em caso de dúvidas, consulte a redação: raeredacao@fgvsp.br.

A RAE-eletrônica é a revista on-line da FGV-EAESP, totalmente aberta e criada com o objetivo de agilizar a veiculação de trabalhos inéditos. Lançada em janeiro de 2002, com perfil acadêmico, é dedicada a professores, pesquisadores e estudantes. Para mais informações consulte o site www.rae.com.br/eletronica.

RAE-eletrônica

ISSN 1676-5648

(C2006 Fundação Getulio Vargas - Escola de Administração

de Empresas de São Paulo.

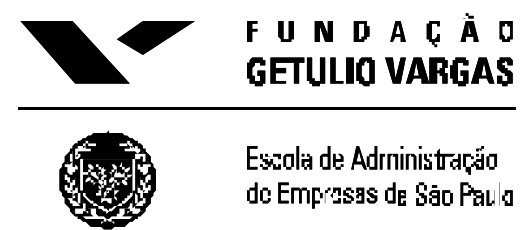




\section{RESUMO}

Este artigo discute os principais fatores considerados pelos executivos na escolha entre diferentes possibilidades de cursos de extensão com base em uma pesquisa realizada com 150 estudantes de cursos de extensão na FGV-EAESP. Após a análise dos dados, identificou-se que o prestígio da escola, a aplicabilidade do conteúdo ministrado e o foco teórico-prático do curso são fatores essenciais para a escolha de cursos de extensão pelos executivos pesquisados. Outro resultado interessante foi observado por meio da divisão dos estudantes em grupos com diferentes interesses, o que possibilitou a segmentação dos cursos para melhor atingir as expectativas dos estudantes. Curiosamente, a maior diferença entre grupos, encontrada por meio da aplicação de análise de clusters, foi entre pessoas que preferem classes homogêneas e as que preferem participar de turmas mais heterogêneas, heterogeneidade esta caracterizada por diferentes posições hierárquicas, formação profissional e área de atuação das empresas em que trabalham.

\section{PALAVRAS-CHAVE}

Cursos de extensão, cursos para executivos, educação continuada, segmentação de cursos, seleção de cursos.

\section{ABSTRACT}

This paper discusses the main factors used by executives to choose among different continuing education courses. It is based upon a survey that was carried out with 150 students attending these courses at the São Paulo School of Business - Getulio Vargas Foundation in São Paulo, Brazil. Data showed that school prestige, applicability of the proposed content and the theoretical/practical focus are essential for the decision about attending course at FGV-EAESP. Another interesting finding was that students could be divided in groups with different interests, which is an invitation to schools to segment their courses, in order to better meet their students' expectations. Curiously, the greatest difference between groups was found after a cluster analysis technique was applied. One group preferred homogeneous classes and the other preferred heterogeneous classes, made up of classmates with differing background, hierarchical positions and working in different industries.

\section{KEYWORDS}


Extension courses, courses for executives, continued education, courses segmentation, course selection.

\section{INTRODUÇÃO}

Este artigo tem como objetivo identificar fatores determinantes na seleção de cursos de educação continuada, definidos aqui como cursos de curta duração (48 a 120 horas em geral) para graduados, em uma área de interesse específica, geralmente equivalente a uma disciplina em um curso de graduação ou pós-graduação. Nessa categoria de curso, englobam-se os cursos orientados para a educação de executivos, que, após um período de vida profissional, se sentem compelidos por diversos fatores a retornar aos bancos escolares. A relevância desta pesquisa está no fato de que, embora existam vários estudos no Brasil e no exterior sobre o ensino de Administração em nível de graduação e pós-graduação, não existem pesquisas voltadas aos cursos de extensão, também conhecidos como educação continuada.

Os objetivos subjacentes à questão central deste trabalho consistem em investigar até que ponto as decisões dos executivos são tomadas objetivamente e de onde decorre a percepção de valor na avaliação de determinado curso.

Procurando responder às questões levantadas primeiramente é feita uma revisão da literatura sobre as expectativas que os executivos têm em relação à sua carreira. Essa revisão é importante porque ajuda a compreender os motivos que levam os executivos a realizarem cursos de educação continuada, permitindo a identificação de possíveis fatores/motivos relevantes na escolha entre as alternativas disponíveis. A seguir são feitas conjecturas sobre a necessidade, por parte dos executivos, de construção de reputação externamente à organização em que atuam para obterem respeitabilidade interna. Também são feitas considerações sobre algumas particularidades das atividades de prestação de serviços, decorrentes da sua intangibilidade, que podem ser úteis para se compreender melhor as dificuldades associadas à escolha de um curso de extensão. Em seguida, é apresentada a metodologia de análise utilizada no trabalho e realizada a análise dos dados coletados na pesquisa. Por fim é feita uma avaliação das limitações desta pesquisa e são tecidas algumas breves conclusões.

\section{EXPECTATIVAS DE CARREIRA DOS EXECUTIVOS}




\section{SELEÇÃO DE CURSOS DE EDUCAÇÃO CONTINUADA POR EXECUTIVOS DE EMPRESAS}

Edmilson Alves de Moraes - Alexandre Reis Graeml - Otávio Próspero Sanchez - Frederico Scott Brusa Mesquita

A percepção dos indivíduos sobre a probabilidade que têm de obter sucesso profissional está relacionada a eventos como transições de carreira e investimentos em educação (Stephens, 1994). No campo de estudo do comportamento nas organizações, a preocupação com as expectativas dos executivos tem sido alvo de estudos em diversas frentes, merecendo destaque, pelo alinhamento com o objetivo do presente trabalho, as seguintes questões: (a) a satisfação no emprego, discutida por Black e Gregersen (1990), Irving e Meyer (1994) e Wanous et al. (1992); (b) a transição de carreira, tratada por Nicholson e West (1988); e (c) as expectativas individuais sobre o sucesso na carreira, com que se preocuparam Stephens, Szajna e Broome (1998).

Esses estudos indicam que os executivos são influenciados pela expectativa de sucesso e tomam decisões que procuram maximizar o retorno de seu investimento educacional em termos de três dimensões: profissional, organizacional e de qualidade de vida.

Na dimensão profissional, a sensação de sucesso está associada à reputação, realizações e reconhecimento extra-organizacional. Na dimensão organizacional, as expectativas de sucesso envolvem ascensão a certo nível hierárquico com determinado nível de remuneração e reconhecimento intraorganizacional. O sucesso na dimensão qualidade de vida está relacionado à capacidade de poder exercer um equilíbrio entre trabalho e não-trabalho, baseado em interesses pessoais (Stephens, Szajna e Broome, 1998).

\section{FATORES DE ESCOLHA DE CURSOS DE EXTENSÃO PELOS EXECUTIVOS}

Há poucas pesquisas até o momento sobre a capacidade individual dos executivos de avaliar adequadamente a oferta educacional. Tampouco existem estudos sobre o impacto das escolhas de cursos de educação continuada sobre as carreiras dos executivos. Não se sabe o quanto esses cursos contribuem, efetivamente, para o sucesso profissional. Cada uma dessas questões mereceria a realização de estudos específicos. Este trabalho não trata especificamente de tais questões, partindo do pressuposto de que os cursos de educação continuada agregam, de alguma forma, valor para aqueles que os realizam, haja vista que há demanda. 
O foco da pesquisa se concentrou em um outro ponto de importância prática para os fornecedores de serviços educacionais, que também é pouco explorado na literatura: a identificação de fatores diferenciadores na seleção de cursos de extensão sob a ótica do executivo.

\section{Necessidade de construção de reputação externa para proporcionar respeitabilidade interna}

O mercado de colocação profissional possui características claras de assimetria de informações (Williamson, 1981), já que as empresas têm poucas possibilidades de avaliar as reais habilidades dos executivos quando os contratam. Somente os próprios executivos conhecem suas reais habilidades (Milgrom e Roberts, 1992) e a carreira na empresa pode ser entendida como uma sequiência de atitudes, atividades e comportamentos associados a papéis profissionais desempenhados ao longo da vida profissional do executivo (Arthur e Lawrence, 1984).

A perspectiva de acesso na carreira do executivo tem aspectos objetivos, ou externos, e subjetivos, ou internos, relativos à percepção do executivo. Os aspectos objetivos são eventos observáveis relativos ao histórico da vida profissional, como comportamentos e atividades observáveis.

A percepção dos executivos sobre o potencial de ascensão profissional é afetada por aspectos subjetivos, como reputação de realizações no local de trabalho (Stephens, 1994). Entretanto, a existência de normas e regras na organização pode dificultar a construção dessa reputação, já que nem sempre há oportunidades reais para que os executivos obtenham os resultados necessários para construir a reputação desejada (Caldas, 1992).

Portanto é possível que os executivos procurem construir suas reputações fora das organizações, buscando atestar externamente suas credenciais, por meio de certificados e diplomas de cursos realizados em escolas de boa reputação, na tentativa de se apoderarem de parte desse prestígio para obter legitimação interna nas empresas em que atuam.

A reputação, se obtida mais facilmente de fora para dentro conforme discutido, poderia tornar-se um importante fator para a sinalização das habilidades do profissional, que, por sua vez, contribuiria para a redução da assimetria de informações no processo de colocação ou recolocação profissional. Ao escolher uma instituição renomada para realizar um curso de extensão, o executivo poderia adquirir credenciais de valor, apropriando-se de parte do prestígio da instituição, que transmite ao mercado um "selo de qualidade" 


\section{SELEÇÃO DE CURSOS DE EDUCAÇÃO CONTINUADA POR EXECUTIVOS DE EMPRESAS}

Edmilson Alves de Moraes - Alexandre Reis Graeml - Otávio Próspero Sanchez - Frederico Scott Brusa Mesquita

desse profissional. $\mathrm{O}$ valor transferido ao executivo constitui-se, entre outros, em valor econômico que o mercado reconhece apenas quando os executivos participam de cursos de primeira linha (The Economist, 1994).

Além da expectativa de sucesso na carreira, os executivos são submetidos a outras pressões, algumas institucionais, como as que apenas legitimam ações que estejam alinhadas com o senso comum de percepção da realidade (Powell e DiMaggio, 1991). Tais forças coercitivas, advindas de origens internas ou externas, tendem a padronizar as características requeridas dos executivos nas organizações, ainda que tais características possam não ter relação direta com as necessidades objetivas das organizações. Em uma clara resposta a esse fator, os executivos são estimulados a obter conformidade e legitimação por meio de cursos de educação continuada que promovam respeitabilidade, atendendo às demandas institucionalizadas no ambiente empresarial.

Tendências isomórficas colaboram na definição dos requisitos a serem atendidos pelos executivos. Entretanto, e somando-se a isso, há pouca margem de manobra nas organizações para a comprovação de características como "visão holística" ou "comportamento proativo". Em um ambiente de negócios instável, as características exigidas dos executivos podem ser conflitantes entre si, na medida em que refletem demandas de stakeholders distintos. Pode-se exigir que o executivo tenha, smultaneamente, extraordinária visão de negócios, preocupe-se preferencialmente com questões ambientais e mantenha o foco nos resultados financeiros do negócio (Kerney, 2002).

É muito improvável que tais requisitos, combinados, sejam demonstrados na atividade diária das empresas, por falta de oportunidades, por falta de métricas ou ainda por serem incompatíveis entre si. Nesse cenário, cursos de extensão podem atrair os executivos por lhes proporcionarem credenciais externas, reconhecidas no mercado de trabalho e mais fáceis de adquirir que o prestígio por realizações internas à organização.

\section{O efeito da intangibilidade da prestação de serviços educacionais}

Uma consulta à literatura permite observar que as organizações têm investido crescentemente no treinamento de seus colaboradores, principalmente devido ao aumento de flexibilidade exigido em decorrência da instabilidade no ambiente de negócios, que passa a requerer habilidades diferenciadas dos profissionais. 


\section{SELEÇÃO DE CURSOS DE EDUCAÇÃO CONTINUADA POR EXECUTIVOS DE EMPRESAS}

Edmilson Alves de Moraes - Alexandre Reis Graeml - Otávio Próspero Sanchez - Frederico Scott Brusa Mesquita

Contudo, há um grau de incerteza significativo a respeito do retorno desse investimento. Existe a preocupação sobre a aplicação na atividade profissional do que é aprendido em cursos de educação executiva, assim como sobre a sustentabilidade de seus efeitos e repercussões (Dutra, Oliveira e Gouveia, 2002).

Do ponto de vista da análise de valor entregue pelos cursos de extensão a executivos, pode-se considerar que se trata de uma prestação de serviços e como tal se poderia imaginar a aplicação de modelos de análise de valor baseados na teoria de escolha do consumidor (Kotler, 2000).

A intangibilidade da prestação de serviços educacionais inclui características que dificultam a avaliação da qualidade oferecida, fator também associado ao fato de que o executivo se torna parte do processo ao interagir com o curso, passando a fazer parte da sua elaboração (Parasuraman, Zeithaml e Berry, 1985). Parasuraman, Zeithaml e Berry (1988) propuseram a escala SERVQUAL para avaliação de qualidade na prestação de serviços, considerando que certas atividades procuram atender expectativas dos clientes que a empresa apenas é capaz de supor como existentes. Existem falhas de entendimento e implementação que esses autores chamam de lacunas (gaps). Além disso, na prestação de serviços, o agente prestador, no caso dos serviços educacionais, o instrutor, é muito importante no resultado final da prestação de serviços (Johnston, 1995).

\section{MÉTODO EMPREGADO}

Os aspectos que envolvem a análise da qualidade de serviços vêm sendo pesquisados com razoável frequiência. Também aspectos relativos às características desejadas dos prestadores de serviços têm sido mapeados, conforme foi discutido anteriormente. Entretanto, desconhecemos pesquisas conduzidas no sentido de verificar especificamente os fatores determinantes das escolhas de cursos de educação continuada por executivos.

Assim, optou-se pela realização de uma pesquisa exploratória baseada na aplicação de questionário. Esta técnica de investigação é composta por um número mais ou menos elevado de questões apresentadas por escrito às pessoas, com objetivo de conhecer opiniões, crenças, interesses, sentimentos, expectativas e situações vivenciadas (Gil, 1989). 


\section{SELEÇÃO DE CURSOS DE EDUCAÇÃO CONTINUADA POR EXECUTIVOS DE EMPRESAS}

Edmilson Alves de Moraes - Alexandre Reis Graeml - Otávio Próspero Sanchez - Frederico Scott Brusa Mesquita

Por questões de facilidade de acesso, a pesquisa foi realizada com alunos de nove cursos de áreas de conhecimento variadas do Programa de Educação Continuada da FGV-EAESP (GVPec), obtendo-se um total de 152 questionários válidos de uma população de 1.380 alunos. A amostra utilizada não foi aleatória, mas de conveniência. Não há garantia de representatividade desta com relação à população dos estudantes em cursos de educação continuada, sobretudo pela grande variedade de ofertas de cursos, por instituições de ensino também bastante diferentes entre si. Acredita-se, porém, que a amostra seja representativa da população de estudantes (executivos) que optam por realizar cursos de extensão na FGV-EAESP, uma vez que as turmas que participaram da pesquisa não destoam de nenhuma forma perceptível do grupo mais abrangente formado por todas as turmas de cursos de extensão oferecidos pela instituição e por ter a amostra um tamanho superior a $10 \%$ da população.

Algumas características da amostra são apresentadas a seguir:

- quanto ao sexo, $53 \%$ são do sexo masculino e $47 \%$ do feminino;

- quanto ao cargo, $11 \%$ estão no nível de diretoria, $41 \%$ em gerência média, $45 \%$ em supervisor/técnico e 3\% não responderam;

- quanto ao setor industrial, $41 \%$ atuam em empresas de manufatura, $51 \%$ em empresas de prestadoras de serviços, $3 \%$ no comércio, $1 \%$ no Terceiro Setor, $1 \%$ no governo e $3 \%$ não responderam;

- o perfil dos respondentes apontou que a faixa de idade dos executivos homens é um pouco mais ampla do que a das mulheres, o que parece representar a inclusão das mulheres no mercado de trabalho, em maior intensidade, em tempos mais recentes;

- a maioria dos executivos que custeiam seus próprios recursos os cursos, ou que tiveram apenas auxílio parcial da empresa, apresenta em média menos tempo de trabalho na empresa atual que os que têm os custos dos cursos custeados exclusivamente pela empresa;

- as empresas são grandes patrocinadoras dos cursos. Os custos de educação de $60 \%$ dos respondentes são assumidos integralmente pelas empresas. A estes se somam $10 \%$ dos respondentes que são custeados parcialmente pelas empresas. 


\section{SELEÇÃO DE CURSOS DE EDUCAÇÃO CONTINUADA POR EXECUTIVOS DE EMPRESAS}

Edmilson Alves de Moraes - Alexandre Reis Graeml - Otávio Próspero Sanchez - Frederico Scott Brusa Mesquita

O questionário utilizado na pesquisa possuía perguntas objetivas, a maioria das quais utilizando escala de medição intervalar, do tipo Likert, que pode ser facilmente submetida a tratamento estatístico. Entre as vantagens da escala de tipo Likert está sua fácil construção e aplicação, além do rápido entendimento pelos entrevistados (Malhotra, 2001).

\section{ANÁLISE DOS RESULTADOS}

O questionário utilizado na pesquisa foi dividido intencionalmente em diversas partes, que procuravam extrair informações distintas dos respondentes e, em alguns casos, obter a confirmação de informações prestadas anteriormente, para fins de verificação de consistência. Assim, alguma redundância foi prevista e estimulada no uso do instrumento de coleta de dados. Os participantes foram levados a apontar fatores genéricos, que considerassem importantes para tomar a decisão sobre a realização de um curso de educação continuada, fatores ligados à escolha do curso atual, motivos adicionais com impacto na decisão e preferências pessoais genéricas. As respostas fornecidas são apresentadas e analisadas a seguir.

\section{Fatores genéricos utilizados na decisão por um curso de extensão}

Foi solicitado que os participantes da pesquisa indicassem 5 fatores, entre os 15 propostos, que mais haviam pesado em sua decisão pela realização do curso de educação continuada em que estavam inscritos naquele momento na FGV-EAESP. Os cinco fatores deveriam ser colocados em ordem, do mais importante até o menos importante. Dos 152 respondentes da pesquisa, 100 fizeram exatamente o que lhes tinha sido solicitado. Outros 41 mencionaram os cinco fatores que consideravam os mais importantes, mas não estabeleceram ordenamento entre eles. Por fim, 11 dos respondentes não preencheram essa parte do questionário.

Os fatores ranqueados pelos 100 participantes que responderam à pergunta conforme solicitado foram tratados de modo que se atribuiu peso 5 ao fator considerado mais importante, peso 4 para o segundo mais importante e assim por diante, até que o quinto fator mais importante recebeu peso 1. Apenas como exemplo, observa-se na Tabela 1 que 28 participantes da pesquisa indicaram o prestígio da instituição como 


\section{SELEÇÃO DE CURSOS DE EDUCAÇÃO CONTINUADA POR EXECUTIVOS DE EMPRESAS}

Edmilson Alves de Moraes - Alexandre Reis Graeml - Otávio Próspero Sanchez - Frederico Scott Brusa Mesquita

o fator mais importante na escolha do curso. O preço do curso, por sua vez, não foi mencionado por nenhum dos pesquisados como sendo um dos três fatores mais importantes. Dos 100 respondentes, apenas 7 mencionam o preço como fator de decisão importante e, ainda assim, apenas como o quarto ou quinto item no ranking.

As duas últimas linhas da Tabela 1 apresentam, respectivamente, a quantidade de vezes que um fator foi mencionado e a pontuação obtida para o fator, por meio da soma dos produtos das quantidades de citações pelos pesos a elas atribuídos (em função da sua posição na escala de importância).

\section{Tabela 1 - Importância atribuída aos possíveis fatores de seleção de curso de extensão}

\begin{tabular}{|c|c|c|c|c|c|c|c|c|c|c|c|c|c|c|c|}
\hline Peso & 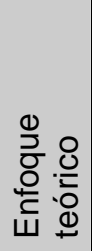 & 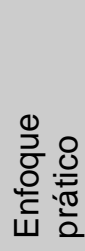 & 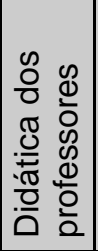 & 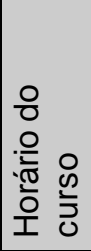 & 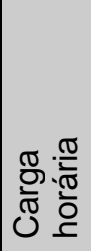 & 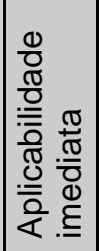 & 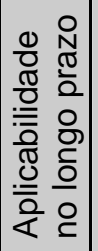 & 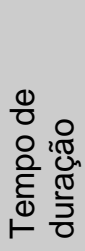 & 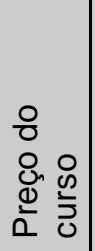 & 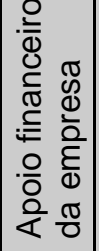 & 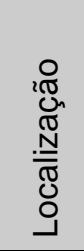 & 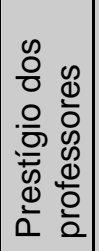 & 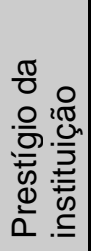 & 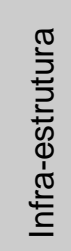 & 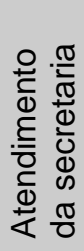 \\
\hline Cinco & 7 & 15 & 1 & 2 & 2 & 25 & 10 & 0 & 0 & 8 & 0 & 1 & 28 & 0 & 1 \\
\hline Quatro & 9 & 14 & 3 & 2 & 2 & 15 & 12 & 3 & 0 & 4 & 0 & 14 & 20 & 2 & 0 \\
\hline Três & 10 & 12 & 5 & 7 & 6 & 11 & 10 & 4 & 0 & 8 & 3 & 12 & 10 & 2 & 0 \\
\hline Dois & 11 & 14 & 4 & 10 & 6 & 8 & 8 & 4 & 4 & 4 & 3 & 7 & 13 & 4 & 0 \\
\hline Um & 4 & 13 & 4 & 11 & 11 & 2 & 8 & 8 & 3 & 10 & 6 & 5 & 14 & 1 & 0 \\
\hline Quant. & 41 & 68 & 17 & 32 & 27 & 61 & 48 & 19 & 7 & 34 & 12 & 39 & 85 & 9 & 1 \\
\hline Pontos & 127 & 208 & 44 & 70 & 59 & 236 & 152 & 40 & 11 & 98 & 21 & 116 & 290 & 23 & 5 \\
\hline
\end{tabular}

A abordagem utilizando ponderação - soma dos produtos dos números de citações pelos pesos relacionados ao seu ordenamento - só é possível quando se flexibiliza o rigor metodológico. Como foi solicitado aos respondentes que apenas ordenassem os fatores considerados mais importantes, sem indicar por que um fator seria mais importante do que o outro, não foi possível afirmar que a "distância" que separa um fator do outro no ordenamento obtido seja constante, condição necessária para a aplicação da ponderação sem restrições. Em termos estatísticos, o problema é que se dispõe de uma escala ordinal para a qual se deseja utilizar um tratamento que é adequado apenas para escalas intervalares (Malhotra, 2001).

Embora não seja um procedimento metodologicamente perfeito, a pontuação ponderada pode ser útil na análise dos dados, se não houver motivos para acreditar que a escala ordinal obtida seja muito diferente de uma escala intervalar. A ponderação, quando comparada à simples soma do número de citações, contida na penúltima linha da Tabela 1 (linha "Quant."), possui a vantagem de não desprezar o ordenamento por importância proposto pelos participantes da pesquisa para os cinco fatores. 


\section{Fatores relacionados especificamente à escolha do curso atual}

Os participantes da pesquisa foram convidados a expressar os motivos que os levaram a escolher especificamente o curso que estavam realizando no momento, por meio das questões apresentadas na Figura 1, enunciadas utilizando-se escala tipo Likert de 7 pontos.

Figura 1 - Perguntas do questionário para o levantamento dos motivos que levaram à escolha do curso atual

\begin{tabular}{|c|c|c|c|c|c|c|c|}
\hline \multicolumn{8}{|c|}{ Dentre os motivos que me levaram a escolher este curso estão: } \\
\hline 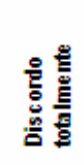 & 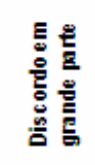 & 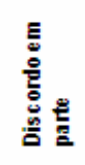 & 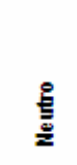 & 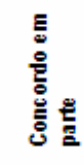 & 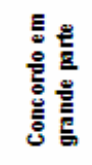 & 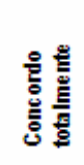 & \\
\hline [1] & [2] & [3] & [4] & {$[5]$} & {$[6]$} & [7] & $\begin{array}{l}\text { MOT1 Aprender sobre técnicas/métodos que possam ser úteis em } \\
\text { situações futuras. }\end{array}$ \\
\hline [1] & [2] & [3] & {$[4]$} & {$[5]$} & {$[6]$} & [7] & $\begin{array}{l}\text { MOT2 Aproveitar o incentivo oferecido pela empresa (pagamento } \\
\text { parcial ou total do curso). }\end{array}$ \\
\hline [1] & [2] & [3] & [4] & {$[5]$} & {$[6]$} & [7] & Мот3 Atender a uma solicitação especifica da chefia. \\
\hline [1] & {$[2]$} & [3] & [4] & {$[5]$} & {$[6]$} & [7] & $\begin{array}{l}\text { MOT4 Encontrar soluções para problemas especificos imediatos } \\
\text { vivenciados na empresa. }\end{array}$ \\
\hline [1] & [2] & [3] & [4] & {$[5]$} & [6] & [7] & MOT5 Facilitar a ascensão dentro da empresa. \\
\hline [1] & [2] & [3] & [4] & [5] & [6] & [7] & MOT6 Fazer contato com outros profissionais da mesma área. \\
\hline [1] & {$[2]$} & [3] & [4] & {$[5]$} & {$[6]$} & [7] & MOT7 Fazer contato com profissionais de outras áreas. \\
\hline$[1]$ & [2] & [3] & {$[4]$} & {$[5]$} & {$[6]$} & [7] & MOT8 Melhorar a percepção que outras pessoas têm a meu respeito \\
\hline [1] & [2] & [3] & [4] & {$[5]$} & {$[6]$} & [7] & MOT9 Melhorar o meu curriculo. \\
\hline [1] & {$[2]$} & [3] & [4] & {$[5]$} & {$[6]$} & [7] & MOT10 Mudar a área de atuação profissional. \\
\hline [1] & [2] & [3] & [4] & [5] & {$[6]$} & [7] & MOT11 Reciclar meus conhecimentos. \\
\hline
\end{tabular}

Nas respostas obtidas se destacaram a importância de aprender novas técnicas para solução de problemas futuros, reciclagem do conhecimento e melhoria do próprio currículo. Além desses, o aprendizado de técnicas para a solução de problemas imediatos também se mostrou relativamente importante. 


\section{SELEÇÃO DE CURSOS DE EDUCAÇÃO CONTINUADA POR EXECUTIVOS DE EMPRESAS}

Edmilson Alves de Moraes - Alexandre Reis Graeml - Otávio Próspero Sanchez - Frederico Scott Brusa Mesquita

\section{Motivos adicionais que pesaram na decisão pelo curso atual}

As questões na Figura 2 foram apresentadas na sequiência aos respondentes do questionário. Esta parte do questionário também se baseou em escala intervalar tipo Likert de 7 pontos.

\section{Figura 2 - Perguntas de levantamento dos motivos adicionais para a escolha do curso atual}

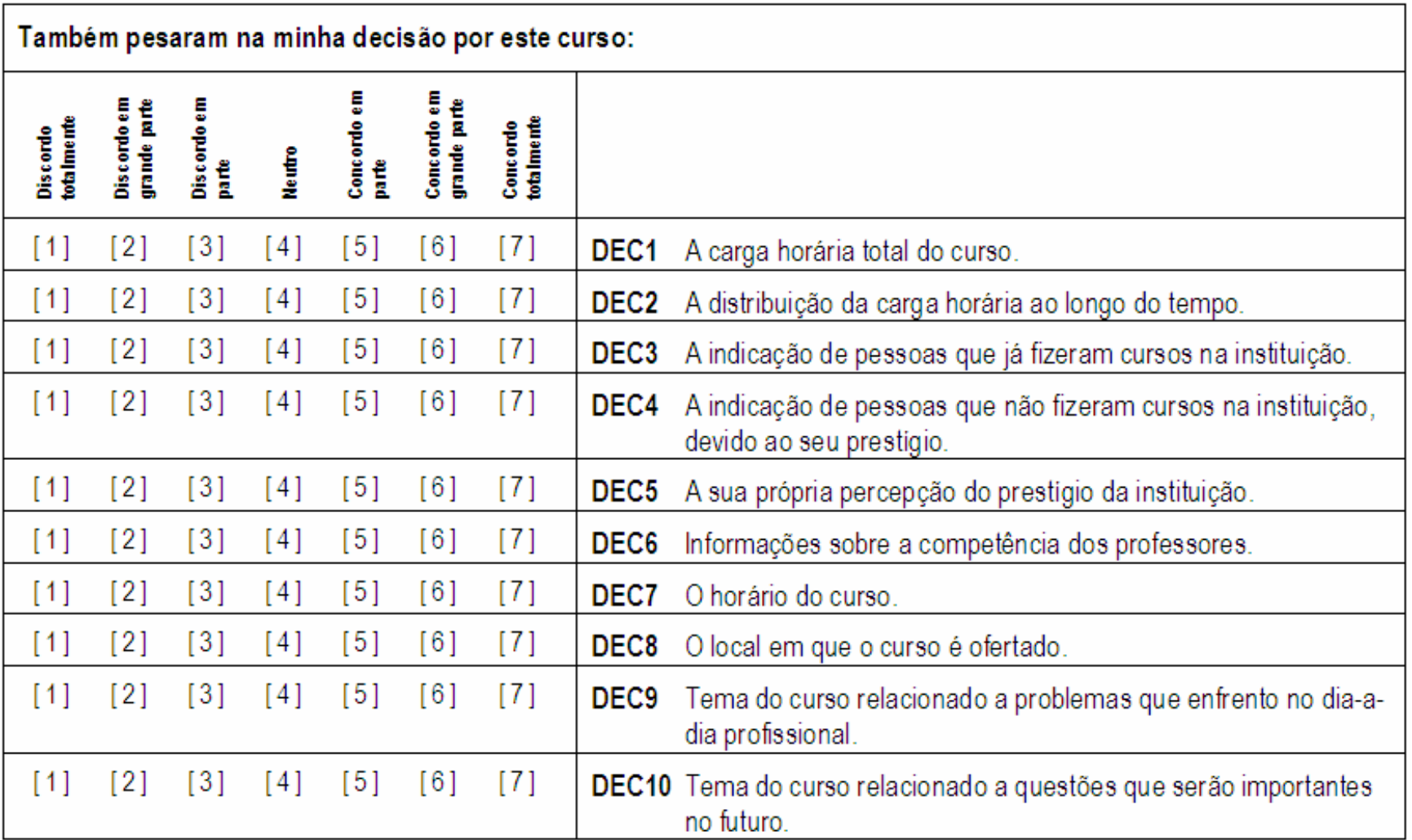

Os resultados desse conjunto de questões foram os seguintes:

- a carga horária total do curso pesou na decisão de $75 \%$ dos participantes da pesquisa, mas a distribuição da carga horária ao longo do tempo, como já era de se esperar, foi essencial na tomada de decisão;

- a indicação de pessoas que já realizaram cursos na instituição influiu na escolha de boa parte dos respondentes. Essa constatação mostra que os participantes na pesquisa procuraram obter informações "primárias" para a tomada de decisão, não confiando apenas no prestígio da instituição, apesar de este ter sido um fator preponderante; 
- informações sobre a competência dos professores foram consideradas, embora não se tenha explorado a questão de como os respondentes tiveram acesso a essa informação. É provável que haja uma transferência inconsciente do prestígio da instituição para os professores;

- horário e local do curso também tiveram impacto sobre a decisão de escolha do curso. Isso é perfeitamente compreensível considerando-se que se trata de cursos ofertados em uma grande metrópole (São Paulo), com tráfico intenso de veículos e grande dispersão geográfica;

- o tema do curso também foi muito importante na escolha do programa de educação continuada. Verificou-se que os participantes da pesquisa valorizam questões de interesse imediato e de interesse futuro. Três quartos deles concordaram em grande parte ou totalmente com as afirmações 'temas relacionados a problemas enfrentados no dia-a-dia pesaram na decisão pelo curso" e "temas relacionados a questões que serão importantes no futuro pesaram na decisão pelo curso".

\section{Preferências pessoais genéricas}

O questionário também continha algumas perguntas sobre preferências genéricas dos participantes, que podem ser utilizadas pela instituição de ensino para preparar novos cursos mais ajustados às necessidades e preferências do seu público-alvo. A Figura 3 apresenta essa seção do questionário.

Figura 3 - Preferências pessoais

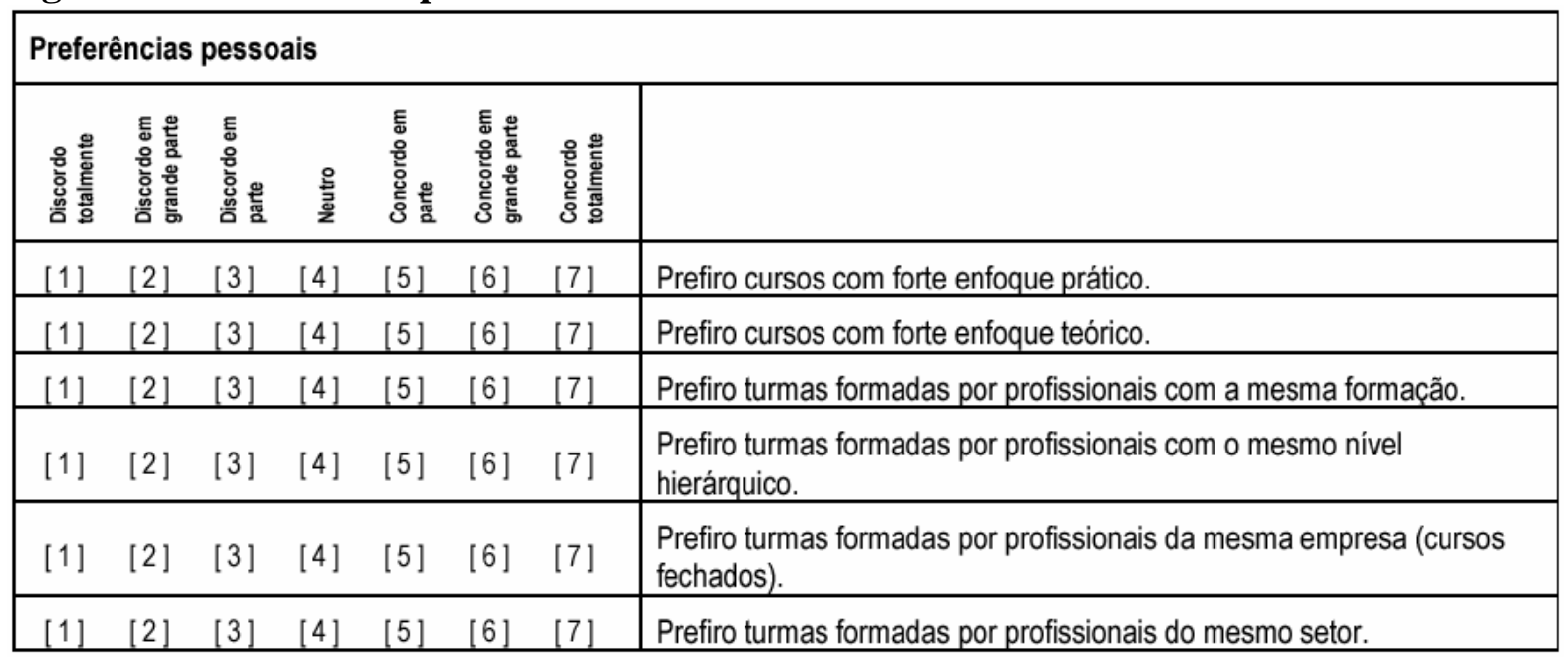




\section{SELEÇÃO DE CURSOS DE EDUCAÇÃO CONTINUADA POR EXECUTIVOS DE EMPRESAS}

Edmilson Alves de Moraes - Alexandre Reis Graeml - Otávio Próspero Sanchez - Frederico Scott Brusa Mesquita

Observou-se, nesse conjunto de questões, uma grande preferência por cursos com enfoque prático. Parece existir algum conflito com informações obtidas de parte anterior do questionário, em que os respondentes consideravam o enfoque teórico como um dos cinco fatores mais importantes para a tomada de decisão sobre a participação em um curso (veja a Tabela 1). É possível que os respondentes realmente tenham conseguido fazer a distinção, como esclarece o relato a seguir: "considero importante fazer cursos com enfoque teórico aprofundado, mas agora que estão perguntando sobre minhas preferências, prefiro fazer cursos práticos".

As opiniões sobre se as turmas deveriam ser montadas levando-se em consideração as características dos participantes, o nível hierárquico dentro das empresas ou aspectos de setor e empresa apontam aparentemente para uma preferência pela diversidade em todos os aspectos, ainda que não muito acentuada. Entretanto, como será discutido posteriormente na análise de clusters, essa dispersão foi em algum grau provocada pela existência de dois grupos bastante distintos de pessoas, com relação à preferência por turmas mais homogêneas ou mais heterogêneas.

\section{Identificação de fatores por meio de análise multivariada}

Após a análise preliminar dos dados, procurou-se identificar se haveria fatores comuns entre as variáveis pesquisadas que fossem responsáveis pela variabilidade dos dados. Para isso, foi utilizada a técnica de análise fatorial, realizada com o software estatístico MiniTab. Foram utilizadas para análise apenas as perguntas sobre motivos (MOT1 a MOT11) e decisões (DEC1 a DEC10), constantes das Figuras 1 e 2 respectivamente, sendo os resultados relevantes mostrados em destaque.

A análise fatorial mostrou que não há um grupo pequeno de fatores que consiga explicar uma parcela muito significativa da variância dos dados. Entretanto, os cinco fatores apresentados explicam $50 \%$ da variabilidade dos dados, o que não pode ser considerado desprezível.

Procurou-se nomear os fatores a partir das variáveis que mais caracterizavam cada um deles. Assim, o primeiro fator, com um forte índice negativo em todas as variáveis, foi denominado indiferença. O segundo fator demonstrava claramente uma ligação com a solução de problemas específicos imediatos ou cotidianos (MOT4), bem como a ascensão na carreira (MOT5). Assim, resolveu-se denominar esse fator de pragmatismo. O terceiro fator se relaciona à solicitação da chefia (MOT3), mas, ainda mais intensamente, a 


\section{SELEÇÃO DE CURSOS DE EDUCAÇÃO CONTINUADA POR EXECUTIVOS DE EMPRESAS}

Edmilson Alves de Moraes - Alexandre Reis Graeml - Otávio Próspero Sanchez - Frederico Scott Brusa Mesquita

incentivos da empresa (MOT2). Por isso, esse fator foi denominado de necessidade corporativa. Por sua vez, o fator 4 possuiu um forte componente ligado à questão da indicação (DEC4) e, em menor grau, a uma mudança na área profissional (MOT10), sendo denominado de mobilidade. Finalmente, o fator 5, ligado diretamente à reciclagem de conhecimentos (MOT11) e à competência dos professores (DEC6), foi denominado de desenvolvimento pessoal.

Feitas essas considerações, pode-se dizer que pragmatismo, mobilidade, desenvolvimento pessoal e necessidade corporativa estariam entre os fatores que mais explicam as respostas da pesquisa. Infelizmente, o fator 1, que é o principal fator, é também o mais difícil de ser interpretado e talvez aponte para a necessidade de refinar a pesquisa e os motivos levantados. É possível que algum aspecto relevante não tenha sido incluído nas perguntas do questionário e esteja sendo tratado de forma subjacente pelos participantes da pesquisa. Outra possibilidade é algum grau de inconsistência nas respostas oferecidas pelos respondentes.

\section{Segmentos de mercado para cursos de educação continuada}

A análise realizada nas seções anteriores preocupou-se em detectar padrões e tendências gerais para todo o grupo de participantes da pesquisa. Nessa seção, será descrito o procedimento adotado para procurar descobrir se existiam subconjuntos de pessoas com motivos significativamente diferentes para a escolha de um curso de extensão. Esse tipo de avaliação é importante porque pode contribuir para os critérios de segmentação dos cursos oferecidos pela instituição, de modo a atender mais adequadamente às expectativas e aos interesses de diferentes grupos de alunos em potencial.

Optou-se por realizar uma análise de clusters com base nas afirmações que apresentaram maior dispersão nas análises anteriores. Especial atenção foi dada àquelas questões para as quais aproximadamente metade dos participantes respondeu favoravelmente e a outra metade respondeu contrariamente. Assim, decidiu-se utilizar as respostas às seguintes afirmações do questionário na tentativa de formação de agrupamentos significativos:

- fazer contato com outros profissionais da mesma área;

- melhorar a percepção que outras pessoas têm a meu respeito;

- mudar a área de atuação profissional; 
- prefiro turmas formadas por profissionais com a mesma formação;

- prefiro turmas formadas por profissionais com o mesmo nível hierárquico;

- prefiro turmas formadas por profissionais do mesmo setor.

Utilizou-se o método de agrupamento k-means, disponibilizado no software estatístico MiniTab, que utiliza um algoritmo não hierárquico para a geração de um número de agrupamentos predefinido pelo analista. Optou-se pela geração de dois agrupamentos que acabaram se distinguindo, principalmente, em função da preferência dos seus integrantes por um maior ou menor grau de homogeneidade da turma do curso. Assim, esses grupos foram chamados de "não sectários" (grupo 1) e "ligeiramente sectários" (grupo 2). O motivo de se chamar o segundo grupo de "ligeiramente sectários", e não "sectários", foi a postura dos seus integrantes, em geral de indiferença ou leve concordância com as afirmações propostas no questionário sobre a preferência por turmas homogêneas.

O grupo dos "não sectários" (grupo 1) ficou formado por 59 integrantes e o grupo dos "ligeiramente sectários" (grupo 2) contou com 75 integrantes, de acordo com a divisão realizada utilizando-se o algoritmo $k$ means. A base de dados contava com informações utilizáveis de 134 questionários para esta análise, já que alguns questionários tiveram que ser descartados, por não terem sido completamente preenchidos.

Para a tabulação e a análise das respostas obtidas, optou-se pela utilização de gráficos box-plot. Esse tipo de gráfico - também conhecido como box and wisker - é uma representação visual útil de uma coleção de dados, porque permite o rápido reconhecimento dos quartis, mediana e outliers. A "caixa" corresponde à dispersão dos dados entre o primeiro quartil (limite inferior da "caixa") e o terceiro quartil (limite superior da "caixa"). O traço dentro da "caixa", quando há, representa a mediana. O "bigode" superior à caixa central representa os valores acima do terceiro quartil e o inferior representa os valores abaixo do primeiro quartil. Os asteriscos acima ou abaixo dos "bigodes" representam os outliers. Por meio desse gráfico podemos verificar qual a dispersão nas respostas dadas a cada uma das alternativas.

As características dos dois grupos, com relação à preferência por homogeneidade/heterogeneidade das turmas dos cursos, ficam claramente evidenciadas a partir da análise dos gráficos box-plot apresentados na Figuras 4.

Figura 4 - Discriminação das preferências entre os grupos obtidos a partir da análise de clusters com $k$-means 


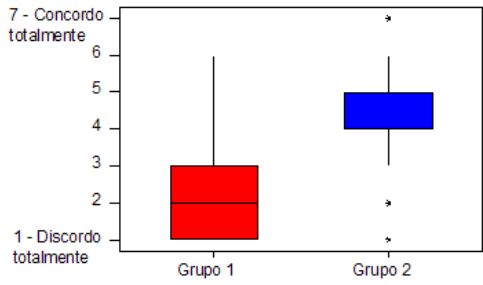

a) Prefiro turmas formadas por profissionais com a mesma formação

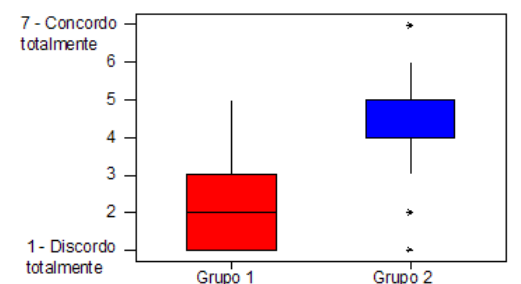

b) Prefiro turmas formadas por profissionais com o mesmo nível hierárquico

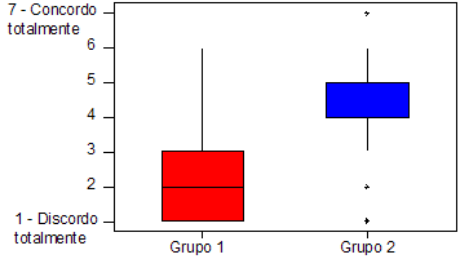

c) Prefiro turmas formadas por profissionais do mesmo setor

Outras diferenças observadas entre os grupos foram menos significativas, mas ainda assim dignas de menção, são as seguintes:

- os membros do grupo dos "não sectários" são parcial ou totalmente patrocinados por suas empresas em uma proporção inferior aos membros do grupo dos "ligeiramente sectários" (62\% no caso dos "não sectários" e $72 \%$ no caso dos "ligeiramente sectários");

- no grupo dos "hão sectários" a proporção de pessoas que têm cargos de supervisão/técnicos é inferior à que ocorre no grupo dos "ligeiramente sectários" (45,6\% contra 52,1\%), enquanto a proporção de pessoas em cargos de diretoria apresenta diferença oposta (12,3\% contra 6,8\%), ou seja, o grupo dos "não sectários" possui, percentualmente, mais estrategistas e menos profissionais técnico-operacionais do que o grupo dos "ligeiramente sectários". Essa diferença reforça a idéia do senso comum de que a alta cúpula das empresas possui interesses mais generalistas e que técnicos são mais especializados, embora este estudo não tenha o objetivo de aprofundar essa discussão nem elementos científicos para tal;

- apesar de a grande maioria dos participantes da pesquisa ser proveniente de grandes empresas, a proporção é diferente entre "não sectários" (48,2\%) e "ligeiramente sectários" (54,1\%). A proporção de respondentes que atuam em empresas que possuem de 100 a 500 funcionários foi significativamente maior no grupo dos "não sectários" (26,8\%) do que no dos "ligeiramente sectários" (17,6\%). Entre os "não sectários", a proporção de empresas com até 100 funcionários foi de $12,5 \%$ (contra 13,5\% dos "ligeiramente sectários") e de empresas entre 500 e 1000 funcionários foi também de 12,5\% (contra 14,9\% dos "ligeiramente sectários");

- curiosamente os cinco participantes provenientes de empresas do comércio, os dois provenientes de empresas do governo e o único participante do Terceiro Setor ficaram todos no grupo dos 
"ligeiramente sectários". A grande maioria dos respondentes pertencia ao setor industrial e de serviços, cuja distribuição ficou da seguinte forma (desconsiderando-se os participantes do comércio, governo e $\mathrm{ONG})$ :

○ indústria - "não sectários", 45,8\%; "ligeiramente sectários", 42,4,3\%;

○ serviços - "não sectários”, 50,8\%; "ligeiramente sectários”, 57,6\%.

- 13,6\% dos integrantes do grupo dos "não sectários" estão realizando seu primeiro curso de educação continuada. Esse número sobe para $24 \%$, no caso dos "ligeiramente sectários". Isso permite a conjectura de que, depois de ter realizado outros cursos de extensão, o aluno percebe a contribuição positiva de turmas mais heterogêneas, o que seria um interessante tópico para estudos posteriores.

\section{CONSIDERAÇÕES FINAIS}

Como esta pesquisa foi realizada apenas com alunos dos cursos de educação continuada da FGV-EAESP, ela reflete a forma como os executivos pesquisados tomam decisões sobre a continuidade da sua formação acadêmica. Deve-se tomar o cuidado de não extrapolar as conclusões obtidas a partir desta amostra para populações distintas daquela que ela representa. Instituições de menos renome conseguem oferecer bons cursos e atender bem às expectativas e necessidades dos seus alunos, que podem ser diferentes das detectadas neste estudo.

O fato de os alunos escolherem instituições de prestígio principalmente em função dessa característica lhes atribui uma responsabilidade ainda maior, visto que os cursos devem ser capazes de atender à expectativa gerada em torno do seu prestígio, o que não é tarefa das mais fáceis.

Talvez a principal conclusão que se possa tirar de um resultado tão diverso de fatores seja a existência de vários pequenos nichos para cada um dos grupos identificados e principalmente a grande necessidade de uma comunicação eficiente do foco de cada curso e do perfil desejado dos alunos.

Entre as questões abertas pela pesquisa para futuros estudos está uma comparação dos resultados obtidos com os originados a partir da sua aplicação em outras instituições, tanto naquelas cuja percepção de 
qualidade por parte do mercado seja distinta quanto nas vistas como concorrentes diretas. Tal comparação poderia ser realizada procurando-se verificar semelhanças e diferenças entre esses grupos.

A condução desse tipo de pesquisa com candidatos potenciais que nunca tivessem participado de cursos de educação continuada poderia levar a um entendimento das prioridades no processo de escolha (tipo de curso ou instituição, por exemplo). Poder-se-ia então controlar a variável "curso" porque um mesmo candidato compara diversas instituições em função de cursos similares. A utilização de candidatos potenciais também serviria ao propósito das instituições de verificar sua posição competitiva em relação às demais.

\section{REFERÊNCIAS BIBLIOGRÁFICAS}

ARTHUR, M. B.; LAWRENCE, B. S. Perspectives on environment and career: An introduction. Journal of Occupacional Behaviour, v. 5, p. 1-8, 1984.

KERNEY, A. T. A Vision of Tomorrow's Corporate World. Davos, Future Leaders Forum, fev. 2002.

BLACK, J. S.; GREGERSEN, H. B. Expectations, satisfaction, and intention to leave of American expatriate managers in Japan. International Journal of Intercultural Relations, v. 14, p. 485-506, 1990.

CALDAS, M. P. Carreira e mobilidade de executivos: 1988-1991: pesquisa de executivos em processo de demissão e uma contribuição ao estudo do “outplacement” no Brasil. 2002. Dissertação (Mestrado), Escola de Administração de São Paulo, São Paulo, 1992.

DUTRA, H. F. O.; OLIVEIRA, P. A. S.; GOUVEIA, T. B. Avaliando a Qualidade de Serviço numa Instituição de Ensino Superior. In: ENCONTRO ANUAL DA ASSOCIAÇÃO NACIONAL DOS PROGRAMAS DE PÓS-GRADUAÇÃO EM ADMINISTRAÇÃO, 2002, Rio de Janeiro, São Paulo. Anais. Rio de Janeiro: ANPAD, 2002.

GIL, A. C. Como elaborar projetos de pesquisa. São Paulo: Atlas, 1989. 
IRVING, P. G.; MEYER, J. P. Reexamination of the met expectations hypothesis: A longitudinal analysis. Journal of Applied Psychology, v. 79, p. 937-49, 1994.

JOHNSTON, R. The Determinants of Service Quality: Satisfiers and Dissatisfiers. International Journal of Service Industry Management, v. 6, n. 5, p. 53-71, 1995.

KOTLER, P. Administração de marketing. São Paulo: Prentice-Hall, 2000.

MALHOTRA, N. K. Pesquisa de marketing: uma orientação aplicada. Porto Alegre: Bookman, 2001.

MILGROM, R. Economics, Organization and Management. Upper Saddle River, New Jersey: PrenticeHall, 1992.

NICHOLSON, N.; WEST, M. Managerial job change: men and women in transition. New York: Cambridge University Press, 1988.

PARASURAMAN, A.; ZEITHAML, V. A.; BERRY, L. L. SERVQUAL: A Multiple-Item Scale for Measuring Customer Perceptions of Service Quality. Journal of Retailing, v. 64, n. 1, p. 12-40, spring 1988.

PARASURAMAN, A.; ZEITHAML, V. A.; BERRY, L. L. A conceptual model of service quality and its implications for future research. Journal of marketing, v. 49, n. 4, p. 41-50, fall 1985.

POWELl, W. W.; DiMAGGIO, P. J. (Eds.). The New Institucionalism in Organizational Analysis. University of Chicago Press, 1991.

STEPHENS, G. K. Crossing internal career boundaries: The state of research on subjective career transitions. Journal of Management, v. 20, n. 2, p. 479-501, 1994. 
STEPHENS, G. K.; SZAJNA, B.; BROOME, K. M. The career success expectations scale: an exploratory and confirmatory factor analysis. Educational and Psychological Measurements Review, v. 58, n. 1, p. 129-42, fev. 1998.

THE ECONOMIST. The MBA cost-benefit analisys; The Economist, London, 6 ago. 1994. p.58.

WANOUS, J. P.; POLAND, T. D.; PREMACK, S. L.; DAVIS, K. S. The effects of met expectations on newcomer attitudes and behaviors: A review and meta-analysis. Journal of Applied Psychology, v. 77, n. 3, p. $288-97,1992$.

WILLIAMSON, O. E. The economics of organization: The transaction cost approach. American Journal of Sociology, v. 87, n. 3, p. 548-75, nov. 1981. 


\section{Artigo recebido em 17.08.2003. Aprovado em 16.03.2006.}

\section{Edmilson Alves de Moraes}

Professor da FGV-EAESP e do Centro Universitário da FEI. Doutor em Administração de Empresas pela FGV-EAESP.

Interesses de pesquisa nas áreas de métodos quantitativos aplicados à administração, estratégia e gestão da inovação.

E-mail: edmilson@fgvsp.br

Endereço: Rua João Belletato, 33, ap. 32, Vila Bastos, Santo André - SP, 09040-230.

\section{Alexandre Reis Graeml}

Professor do programa de mestrado do Centro Universitário Positivo e da Universidade Tecnológica Federal do Paraná. Doutor em Administração de Empresas pela FGV-EAESP.

Interesses de pesquisa nas áreas de tecnologia da informação e administração estratégica da produção.

E-mail: graeml@fulbrightweb.org

Endereço: Rua Chichorro Junior, 364, apto. 504, Curitiba - PR, CEP 80035-040.

\section{Otávio Próspero Sanchez}

Professor da FGV-EAESP e da Universidade Metodista de São Paulo. Doutor em Administração de Empresas pela FGV-EAESP.

Interesses de pesquisa nas áreas de tecnologia da informação, economia, estratégia e inovação.

E-mail: otavio@fgvsp.br

Endereço: Rua das Corruíras, 901 - São Bernardo do Campo - SP - CEP 09861-100.

\section{Frederico Scott Brusa Mesquita}

Doutorado em Administração de Empresas pela FGV-EAESP.

Interesses de pesquisa nas áreas de gestão do conhecimento, gestão de serviços e e-business.

E-mail: fred@gestaodoconhecimento.com.br

Endereço: Rua dos Flamboyants 108, Carvoeira - Florianópolis - SC 88040-550. 